\title{
Oral tolerance of Caloreen in babies
}

\author{
G RUSSELL AND C COSTALOS \\ Department of Neonatal Paediatrics, Aherdeen Maternity Hospital
}

SUMMARY Serial plasma glucose concentrations were compared in 20 infants of low birthweights $(<2500 \mathrm{~g})$ after test meals of $10 \%$ solutions of Caloreen and glucose. After Caloreen, the rise in plasma glucose concentration occurred more slowly but was better sustained, and hyperglycaemia was seen less often than after glucose. Caloreen may be preferable to glucose as a carbohydrate source in the prophylaxis and treatment of neonatal hypoglycaemia.

In a previous study ${ }^{1}$ we showed that solutions of Caloreen*, a glucose polymer, consistently left the stomach of the newborn infant more rapidly than glucose solutions of similar strength. We speculated that this might be due to failure of enzymatic degradation of Caloreen resulting in lack of stimulation of the duodenal osmoreceptors; if this were so, Caloreen might not be absorbed and would therefore offer no advantage over glucose as a carbohydrate source in neonatal nutrition, although this would be out of keeping with our clinical observation that Caloreen is useful in the prophylaxis of neonatal hypoglycaemia. The present study was therefore designed to compare the effects of Caloreen and glucose test meals on plasma glucose concentration.

\section{Methods}

Clinical details of the 20 infants studied are presented in Table 1. Each infant received two consecutive test meals, one of $10 \%$ Caloreen and one of $10 \%$ glucose, the order in which these were given being varied by predetermined random selection. The meals were given at room temperature in a volume of $20 \mathrm{ml} / \mathrm{kg}$ on day $2,24 \mathrm{ml} / \mathrm{kg}$ on day 3 , and $28 \mathrm{mg} / \mathrm{kg}$ on and after day 4 . Plasma glucose

Table 1 Clinical details of 20 low birthweight infants on whom plasma glucose estimations were performed

\begin{tabular}{lccc}
\hline & $\begin{array}{l}\text { Gestation at birth } \\
(\text { weeks })\end{array}$ & $\begin{array}{l}\text { Birthweight } \\
(\mathrm{g})\end{array}$ & $\begin{array}{l}\text { Age at study } \\
(\text { days })\end{array}$ \\
\hline Mean & $34 \cdot 3$ & 1879 & $13 \cdot 7$ \\
SEM & $0 \cdot 63$ & 76 & $2 \cdot 5$ \\
Range & $29-38$ & $1240-2360$ & $2-41$ \\
\hline
\end{tabular}

*Roussel Laboratories Ltd, Wembley Park, Middlesex, England. concentration was estimated using the Beckman $\dagger$ glucose analyser ${ }^{2}$ on plasma obtained from duplicate samples of arterialised capillary blood ${ }^{3}$ taken fasting and at $30,60,120,180$, and 240 minutes after the test meal; the plasma glucose concentration 240 minutes after the first test meal was used as the fasting plasma glucose concentration for the second test meal. The plasma was separated immediately by centrifugation and if immediate analysis was not possible it was stored at $-4^{\circ} \mathrm{C}$ for up to 4 hours. The paired plasma glucose concentrations were compared using Student's $t$ test.

\section{Results}

Plasma glucose concentrations after Caloreen and glucose test meals are shown in Table 2; it can be seen that after Caloreen the rise in plasma glucose concentration was less pronounced but better sustained than after glucose. It was also noted that in individual babies hyperglycaemia occurred more often after glucose (Table 3). One infant developed

Table 2 Plasma glucose concentration after test meals of Caloreen and glucose

\begin{tabular}{|c|c|c|c|c|c|}
\hline \multirow{3}{*}{$\begin{array}{l}\text { Time } \\
\text { after } \\
\text { test } \\
\text { feed } \\
(\mathrm{min})\end{array}$} & \multicolumn{5}{|c|}{ Plasma glucose concentration $(\mathrm{mmol} / \mathrm{l})$} \\
\hline & \multicolumn{2}{|c|}{$\begin{array}{l}\text { After } \\
10 \% \text { Caloreen }\end{array}$} & \multicolumn{2}{|c|}{$\begin{array}{l}\text { After } \\
10 \% \text { glucose }\end{array}$} & \multirow[t]{2}{*}{$P$} \\
\hline & Mean & $S E M$ & Mean & $S E M$ & \\
\hline 0 & $3 \cdot 15$ & $0 \cdot 19$ & $3 \cdot 56$ & $0 \cdot 20$ & $0.2>\mathrm{P}>0.1$ \\
\hline 30 & $6 \cdot 30$ & 0.41 & $7 \cdot 57$ & 0.52 & $0.005>P>0.001$ \\
\hline 60 & $7 \cdot 01$ & 0.43 & 9.41 & $0 \cdot 70$ & $0.001>P$ \\
\hline 120 & $5 \cdot 95$ & 0.49 & $7 \cdot 45$ & 0.56 & $0.05>P>0.025$ \\
\hline 180 & $4 \cdot 30$ & 0.22 & 3.99 & $0 \cdot 32$ & $0.5>P>0.4$ \\
\hline 240 & $3 \cdot 81$ & $0 \cdot 19$ & 2.99 & $0 \cdot 18$ & $0.005>P>0.001$ \\
\hline
\end{tabular}

†Beckman, Glenrothes, Fife, Scotland. 
Table 3 Incidence of hyperglycaemia

\begin{tabular}{lll}
\hline $\begin{array}{l}\text { Plasma glucose } \\
\text { concentration }(\mathrm{mmol} / \mathrm{l})\end{array}$ & \multicolumn{2}{l}{ Number of infants } \\
\cline { 2 - 3 } & After Caloreen & After glucose \\
\hline$>11.0$ & Nil & 9 \\
$>9.5$ & 4 & 18 \\
$>8.0$ & 12 & 29 \\
$>7.5$ & 19 & 35 \\
\hline
\end{tabular}

asymptomatic hypoglycaemia (plasma glucose $1 \cdot 2$ $\mathrm{mmol} / 1 ; 22 \mathrm{mg} / 100 \mathrm{ml}$ ) 4 hours after a glucose feed.

\section{Discussion}

Because of the risks of hyperosmolality and dehydration associated with hyperglycaemia, Lillien $e t$ al. ${ }^{4}$ recommended that neonatal hypoglycaemia be corrected without inducing hyperglycaemia. The tolerance tests reported above show that Caloreen is effective in producing a sustained rise in plasma glucose concentration without the pronounced fluctuation and hyperglycaemia which follow glucose. This lack of fluctuation is similar to that reported after starch meals, ${ }^{5}$ but whereas the blood glucose concentration scarcely rose above the fasting level after starch (maximum rise $1.8 \mathrm{mmol} / 1(35 \mathrm{mg} / 100$ $\mathrm{ml}) 90$ minutes after meal), Caloreen had a much more pronounced effect on plasma glucose (maximum rise $3.9 \mathrm{mmol} / \mathrm{l}(70 \mathrm{mg} / 100 \mathrm{ml}) 60$ minutes after meal). Husband et al. ${ }^{5}$ concluded that starch was hydrolysed slowly in the newborn infant and that given alone it had no part to play in the oral treatment of hypoglycaemia. Caloreen however, in addition to leaving the stomach rapidly and thereby reducing the risks of vomiting and inhalation which are so common at this age, appears to be well absorbed.

The apparent contradiction in the findings that Caloreen leaves the stomach rapidly (suggesting slow or absent hydrolysis) but is well absorbed (suggesting more rapid hydrolysis) may reflect intracellular breakdown of the compound by glucosidases. ${ }^{6}$ There would then be little or no intraluminal conversion of Caloreen to glucose to increase osmolality and hence stimulate the duodenal osmoreceptors which are known to be functional in the newborn. ${ }^{5}$

Caloreen appears to offer two advantages over glucose as a carbohydrate source in neonatal nutrition: it does not delay gastric emptying, and it produces a smoothly sustained rise in plasma glucose concentration. It therefore appears to be particularly suitable for use in the treatment and prophylaxis of neonatal hypoglycaemia.

We thank Dr G Hems for statistical help, Professor A G M Campbell for advice, and Miss Gordon, Pharmacy Department, Royal Aberdeen Children's Hospital, for assistance.

\section{References}

1 Costalos C, Russell G, Al Rahim Q, Blumenthal I, Hanlin S, Ross I. Gastric emptying of Caloreen meals in the newborn. Arch Dis Child 1980; 55: 883-5.

2 Morrison B, Scotland C J, Fleck A. The determination of plasma glucose in a diabetic clinic. Clin Chim Acta 1972; 39: 301-6.

3 Russell G, McKay E. Blood glucose concentration in the perinatal period. Arch Dis Child 1966; 41 : 496-502.

4 Lillien L D, Grajwer L A, Pildes R S. Treatment of neonatal hypoglycemia with continuous intravenous glucose infusion. J Pediatr 1977; 91: 779-82.

5 Husband J, Husband P, Mallinson C N. Gastric emptying of starch meals in the newborn. Lancet 1970; ii: 290-2.

6 Ricketts C R. Glucose polymers in health and disease. In: Mallick N P, ed. The role of Caloreen. Lancaster: MTP Press, 1976: 3-12.

Correspondence to Dr G Russell, Department of Child Health, University Medical Buildings, Foresterhill, Aberdeen AB9 2ZD.

Received 16 October 1979 